\title{
Left Ventricular Ejection Time
}

National Cancer Institute

\section{Source}

National Cancer Institute. Left Ventricular Ejection Time. NCI Thesaurus. Code C74981.

The time it take to eject blood from the left ventricle. Measurement begins when the aortic valve opens and ends when the aortic valve closes. 